\title{
Factors Affecting Adoption of Industry 4.0 by Small- and Medium-Sized Enterprises: A Case in Ho Chi Minh City, Vietnam
}

\author{
Xuan Truong NGUYEN', Quang Khai LUU²
}

Received: April 17, 2020 Revised: April 25, 2020 Accepted: May 07, 2020

\begin{abstract}
The fourth industrial revolution has attracted much academic attention in these past few years. However, research on systematic and extensive factors affecting adoption of Industry 4.0 by SMEs in developing countries, especially in Vietnam, has been unavailable. This study aims to explore the impact of factors that influence the actual adoption of Industry 4.0 by SMEs in Ho Chi Minh City. Mixed-method research was utilized in this study including in-depth interviews of 12 participants and quantitative research of 396 respondents who are representative of SMEs by both online and via paper surveys. The SPSS and SmartPLS 3 software were employed to help analyze the collected data. The results indicate that perceived development of the human resource, perceived on-time, perceived saving cost, perceived improve product quality, perceived saving time, perceived ease-of-use, business resources, and conditions of the business environment, perceived usefulness, perceived enhanced customer relationship, and adoption intention, all have a positive significant effect on actual adoption of Industry 4.0. The results seem to suggest that managerial efforts aimed at increasing the factors' perceptions of adoption of Industry 4.0 and personal relevance of the technology will contribute to implementation success, where success is defined as effectual usage of the Industry 4.0 .
\end{abstract}

Keywords : Industry 4.0, Elements of Industry 4.0, Small and Medium Enterprises, Adoption of Industry 4.0, Ho Chi Minh City.

JEL Classification Code: M16, M30, M31

\section{Introduction}

The context of the industry, as well as the global economy, has changed profoundly in the past few years due to the continuing development and innovation of technology, revolving around the Industrial Revolution. The term first appeared in 2011, coined by the German government as an important initiative for its high-tech strategy (Zhou, 2015). Following the success of the 3 rd Industrial Revolution, the 4th Industrial Revolution refers to the link between independent and autonomous devices, capable of communicating in

${ }^{1}$ FirstAuthor and Corresponding Author. Dean, Marketing Department, University of Finance - Marketing, Vietnam [Postal Address: 2/4 Tran Xuan Soan Street, Tan Thuan Tay Ward, District 7, Ho Chi Minh City, 72910, Vietnam] Email: ts.truong@ufm.edu.vn

${ }^{2}$ Marketing Department, University of Finance - Marketing, Vietnam. Email: quangkhaigib@gmail.com.

(c) Copyright: The Author(s)

This is an Open Access article distributed under the terms of the Creative Commons Attribution Non-Commercial License (http://Creativecommons.org/licenses/by-nc/4.0/) which permits unrestricted noncommercial use, distribution, and reproduction in any medium, provided the original work is properly cited. real-time and possibly the ability to collaborate in a smart environment with other smart devices, thereby making decisions and implementing actions based on the information gathered (Radziwon, Bilberg, Bogers, \& Madsen, 2014). According to Wang, Wan, and Zhang (2016) Industry 4.0 can be classified based on the principles of integration into vertical, horizontal, and end-to-end integration.

With nine core elements of Industry 4.0, such as big data and analytics, collaborative robots, machine-tomachine, cybersecurity, virtual reality, cloud computing, CPS, Internet-of-things, cybersecurity, and simulation (Moeuf, et al., 2018). The connection between people and people, people and machines, and machines and machines are considerable developments, thereby leading to improved productivity, the efficiency of business operations as well as the quality of human life. Accompanied by many benefits that have been demonstrated by previous scientific studies, the Industrial Revolution brought business many benefits as improving product quality, reducing time (Szozda, 2017), and improving cooperation between stakeholders (Oesterreich \& Teuteberg, 2016). Applying Industry 4.0 also hides many great challenges such as high application 
costs, requirements for process and organizational changes, and legal uncertainty (Oesterreich \& Teuteberg, 2016). The UNIDO (2016) announced that one of the most significant challenges of the Industrial Revolution 4.0 is about the awareness and understanding of businesses about the change. Organizations must adapt and actively change their business operations, improve skills, and constantly apply technology.

However, with the acceleration of innovation and the speed of the disruption that the Industrial Revolution 4.0 created, businesses are really hard to understand or predict what will happen shortly even if they possess the best and best-connected information resources. Many industries are witnessing the advent of countless new technologies based on the foundation of the Industrial Revolution 4.0, which is significantly disrupting the current value chain of industries and create a whole new way to run a business. Competition is increasingly fierce and unpredictable when digital platforms allow start-up businesses to stand on par with large and prestigious enterprises in the industry thanks to innovation in the way they operate, from production to sales, distribution to improve quality and value brought to customers. The incredible change in demand is also happening, as transparency is increasing thanks to the connection between people, while digital platforms also allow consumer participation. companies' work, expressed through co-production trends, product co-creation, which forces businesses to change the way operate significantly.

In the constant transformation of the economy, the role of small- and medium-sized enterprises has become increasingly important in many countries around the world including Vietnam. Therefore, this study aims to help SMEs in Ho Chi Minh City to be more aware of the benefits, challenges, and innovations with the speed of the Fourth Industrial Revolution, thereby improving the effectiveness of the adoption of Industry 4.0, thereby helping business activities achieve better results to contribute to the economy in the strong growth momentum of Vietnam. This study was conducted to determine the factors affecting the adoption of Industry 4.0 by businesses in Ho Chi Minh City, the country's economic center. It is the basis of this study to help smalland medium-sized enterprises have a panoramic awareness as well as better understand the Industrial Revolution 4.0. At the same time, this is also the basis for proposing solutions to help industrial applications 4.0 by businesses in the city to become more convenient and efficient to improve business.

\section{Literature Review and Hypotheses}

\subsection{Industry 4.0}

The term Industry 4.0 first appeared at the Hannover Trade Fair in 2011 as the name of a future initiative for the
German government. Kopetz (2011) stated that Industry 4.0 introduces the notion of an Internet of services, where new smart products can exchange their services with other products by machine-to-machine communication (M2M). According to Schwab (2017), the First Industrial Revolution used water and steam power to mechanize production. The Second Industrial Revolution used electric power to create mass production. The Third Industrial Revolution used electronics and information technology to automate production. Now, the Fourth Industrial Revolution is building on the third, the digital revolution that has been occurring since the middle of the last century. It is characterized by a fusion of technologies that is blurring the lines between the physical, digital, and biological spheres.

The Fourth Industrial Revolution is evolving at an exponential speed rather than a linear pace. Moreover, it is disrupting almost every industry in every country. And the breadth and depth of these changes herald the transformation of entire systems of production, management, and governance. The possibilities of billions of people connected by mobile devices, with unprecedented processing power, storage capacity, and access to knowledge, are unlimited. And these possibilities will be multiplied by emerging technology breakthroughs in fields such as artificial intelligence, robotics, the Internet-of-Things, autonomous vehicles, 3-D printing, nanotechnology, biotechnology, materials science, energy storage, and quantum computing. The Industrial Revolution 4.0 includes nine key technological components including Big Data and analytics, Autonomous robots, Simulation, Horizontal and vertical system integration, Internet-of-Things, Cybersecurity, The Cloud, Additive manufacturing, and Augmented reality (Moeuf et al., 2018; Rüßmann et al., 2015).

\subsection{Perceived Saving Time (ST)}

According to Szozda (2017), Industry 4.0, communication between machines and users will be disseminated by technical connections capable of operating in real-time. Operational processes will be managed in the virtual space. Industry 4.0 is the platform that provides solutions based on stream value to eliminate waste, especially the waste of time (Potter, Towill \& Christopher, 2015).

Web-based systems allow instructors and/or students to share materials, submit and return assignments, and communicate online. So, it saves time (Lonn \& Teasley, 2009). Industry 4.0 allows the product model could simply be off to the 'printing' site nearest to the customer, eliminating intermediate manufacturing steps, transportation, and warehousing (Santos et al., 2017). And according to Technology Acceptance Model - TAM, productivity and time savings are a group of factors that impact perceived performance improvement - the main factor that influences 
perceived usefulness. Therefore, the authors propose the hypothesis:

H1. Perceived saving time has a positive influence on perceived usefulness.

\subsection{Perceived Saving Cost (SC)}

According to Szozda (2017), Industry 4.0 helps companies to be fully automated, where the cost-effectiveness of those companies is based on meeting the individual needs of customers, custom production in small quantities, and shipped to customers most reasonably. By electronic factories, focusing on personalization according to customer needs and remote control, companies can operate on a small scale, produce limited quantities, overcome economic scale barriers to maintaining cost competitiveness. Recently, the production chain procedure seems to have changed, since additive manufacturing technology or $3 \mathrm{D}$ printing has transformed its steps. Custom products with difficult geometries can be designed and printed with the help of additive technology. Thus, markets can be supplied without requiring companies to store or produce commodities at great expense (Mavri, 2015). These four levels of operation make Industry 4.0 more productive and cost-saving ( $\mathrm{Lu}$, 2017). The automated tracking of equipment and materials by using embedded sensors can help to reduce material costs (Sardroud, 2012). According to Davis (1989), perceived usefulness is defined as believing that the use of a particular system will improve the result of work. Therefore, the authors propose a hypothesis:

H2. The perceived saving cost has a positive influence on perceived usefulness.

\subsection{Perceived On-Time (PO)}

The Fourth Industrial Revolution has redefined the integration of the physical world in the organization and the cyber world through technologies like artificial intelligence, analytics, cloud technology, Internet-of-Things (IoT), etc. (Akanmu \& Anumba, 2015; Fonseca, 2018). Since then, operating systems in enterprises can integrate with Industry 4.0 for a two-way connection between virtual models and physical models. Technologies such as CPS, RFID allow businesses to build and use tracking systems, monitor asset management, real-time work progress so that they can manage work progress promptly. According to Yuchun \& $\mathrm{Mu}$ (2017), the Internet-of-Things technology has the potential to be used for capturing desired data and information from the production environment in real-time, and the collected data and information can be used for adjusting production schedules corresponding to the changing production environment. And the use of industrial components of Industry 4.0 makes the projects of enterprises completed on time (Oesterreich \& Teuteberg, 2016). Combined with Davis's (1989) announced on the Perceived Usefulness, the authors propose the hypothesis:

H3. Perceived on-time has a positive influence on perceived usefulness.

\subsection{Perceived Improvement Product Quality (PQ)}

According to Matopoulos and Bourlakis (2011), compatibility, as well as increasing levels of cooperation among business parties, help to apply technologies in business operation, increasingly popular and this helps to improve quality significantly. And according to Szozda (2017), products and services are increasingly improved by the adjustment of expectations and characteristics of customers. And simultaneous planning of products and production processes leads to improvements in product quality (Friederichsen \& Keller, 2014). Applications of Industry 4.0 technologies will have a significant impact of the product design and development process, from a planning perspective, technologies can provide an integration of comprehensive and timely updated product data that allow design managers to develop and optimize project plans. During the product design stage, technologies can be used to improve design efficiency and effectiveness (Yin \& Qin, 2019). According to Green, Hevner, \& Collins (2005), perceived increases in software quality enhance the usefulness of the innovation to developers. Combined with Davis's (1989) announced on the Perceived Usefulness, the authors propose the hypothesis:

H4. Perceived improvement product quality has a positive influence on perceived usefulness.

\subsection{Perceived Enhanced Customer Relationship (PR)}

According to Sundblad (2018), many firms managers affirmed that their relationship with customers improved markedly thanks to the integration of data sets within the enterprise, whose elements Industry 4.0 as IoT provides, thereby building a consistent database. Thereby manufacturers can quickly resolve warranty requirements or quality issues. Faster response times also demonstrate transparency in business, increasing customer confidence in businesses.

Based on the applications of Industry 4.0 technology, many barriers to building relationships with the customer have been removed. For instance, co-design activities have been conducted primarily offline and require much 
travel of the company to gather information from various stakeholders such as customers, partners, suppliers, now can be processed easier and faster. Yin and Qin (2019) stated that, through many functions of collaboration platforms, companies now can not only communicate more effectively, but also can review design works in diverse formats (such as $2 \mathrm{D}$ or $3 \mathrm{D}$ ), therefore they can make immediate changes on design and preview the likely impacts of the changes on cost and production.

The state of full digital integration of business as well as manufacturing processes requires employees to have a broader process scope in return (Agostini \& Nosella, 2019). Erol et al. (2016) emphasized that firms should cooperate with external subjects to understand the relationship between process and information flow. Wang, Törngren, and Onori (2015) also proposed that the increasing connectivity of digital integration needs cross-domain collaborations to process. Based on that, Agostini and Nosella (2019) have found a strong correlation between the external relationship of SMEs with Industry 4.0 technologies adoption. Harrigan, Ramsey and Ibbotson (2011) also found that to improve communication with customers, SMEs will adopt internetbased-technologies. Nguyen, Newby and Macaulay (2015) also stated that customer is the main driving force of technology adoption in SMEs. Based on these conclusions, the authors propose the hypothesis:

H5. Perceived enhanced customer relationships have a positive influence on perceived usefulness.

H6. Perceived enhanced customer relationships have a positive influence on adoption intention.

\subsection{Perceived Development of Human Resource (PH)}

Watkins and Marsick (1997) stated that Human Resource Development is a field of research and practice that fosters long-term learning capacity and is related to the work of individuals, groups, and organizational levels. As such, it includes - but is not limited to - training, career development, and organizational development Human Resource Development focus on theory and practice related to training, development, and learning in organizations and individuals in the context of forming an organization's business strategy and competitiveness (Gourlay, 1999). Together with the findings of the authors together with the results from in-depth interviews with industry experts on the work that human resources in enterprises must perform when applying elements of technology 4.0 such as understanding the principles of operation, utility, how to correct and improve elements of Industry 4.0. The authors found, through the work that the business requires its employees to use when using elements of Industry 4.0 and the minimum requirements for the technical skills to use the technology.

Using these elements, human resources in enterprises significantly improve their working capacity and at the same time, it improves the competitive advantages of the business. And combined with the announcement of Davis's perceived usefulness, the authors proposed own hypothesis:

H7. Perceived development of human resources has a positive influence on perceived usefulness.

\subsection{Perceived Usefulness (PU) and Perceived Ease-of- Use (PE)}

According to Davis (1989), Perceiving Usefulness is the level that an individual believes that using technology will improve the performance of their work. Perceived Usefulness is one of the Technology Acceptance Model's primary key determinants for computer acceptance behavior and its importance has been recognized in technology adoption (Agarwal \& Prasad, 1997). Besides, perceived usefulness and perceived ease of use influence the intention to use (Leong, Ooi, Chong, \& Lin, 2011). Perceived Easeof-Use is the level at which an individual believes that using technology will not require effort. According to Suki and Suki (2011) perceived usefulness and perceived usefulness are significant relationships on intention toward using 3G. Lin (2011) tested the perceived ease-of-use and its impact on technology adoption and it has been confirmed that perceived has a significant influence on the application or continued use of technology.

The results of Amoako-Gyampah (2007) indicate that users' perception of the perceived usefulness, ease-of-use of the technology, and the users' level of intrinsic involvement all affect their intention to use the technology. Davis (1989) argued that people in an organization may be forced to use information technology, because information technology has certain benefits for the organization, despite its employees. officials like or dislike using it. At that time, the attitude of the user no longer accurately reflects the usage behavior, but will be intentionally used. This was also applied by Vankatesh et al (2003) in the UTAUT model. This paper considers individuals as businesses with the argument that decisions in the business are always grounded, based on various sources of information coming from the stakeholders of the business to bring about The most benefit is business. Since then, the attitude, like or dislike of employees will not reflect the real behavior, but will be due to the intention factor. On that basis, combined with the announcement of Davis's perceived usefulness and perceived ease-of-use the research team proposes two hypotheses: 
H8. Perceived usefulness has a positive influence on adoption intention.

H9. Perceived ease-of-use has a positive influence on intention adoption.

\subsection{Business Resources (BR)}

According to Ajzen (1991), intentional use includes motivational factors, one of which is perceived behavioral control. Perceived behavioral control reflects how easy or difficult it is to perform the behavior and whether the behavior is controlled or limited. In terms of the relationship between resources and application of technology in SMEs, Potluri and Vajjhala (2018) emphasized that to applicate technologies such as web 3.0, SMEs need to innovate because they have limited financial and human resources. Besides, Potluri and Vajjhala (2018) identified financial and technological challenges, as well as organizational challenges, which are key challenges that SMEs have to face when applying technology. Besides, Ha (2020) found that factors in organizational culture have a positive correlation with the information system such as accounting in Vietnam SMEs. Together with the recent research results had shown that the internal factors of enterprises affect the industrial application behavior of enterprises such as high costs for technical equipment, training and education for employees (Akanmu \& Anumba, 2015), external consulting fees (Smith, 2014), Higher requirements for computer equipment, and the major challenge is to create and develop competencies new, optimize project organization and attract new talent for the workforce, such as employees with shared technical knowledge and integrated experience as the main selection criteria (Oesterreich \& Teuteberg, 2016). Therefore, the authors propose a hypothesis:

H10. Business resources have a positive influence on adoption intention

\subsection{Conditions of Business Environment (CE)}

According to Ajzen (1991), Subjective Norm is a motivating factor affecting application intent. Subjective norms or social influences are defined as "social pressures perceived to perform or not to act". Social influence refers to the impact and impact of important and close people who can influence behavior. As a business, Subjective Norm can now be interpreted as the influence and impact of stakeholders, important and can affect the behavior of businesses such as customers, partners, and suppliers. In terms of the effect of environment on SME's technology adoption, Yoo and Kim (2018) found that environmental factors have a positive correlation with the viability of the technology in the organization and concluded that some aspect of the environment such as securing the competitive edge of market and regulations of facilitating the use of technology has relatively more impact on the viability of firm technology than other factors like technology readiness or organizational factors. Combined with recent research findings on business environment factors that influence industrial application 4.0 of enterprises such as lack of standards and reference architecture, legal uncertainty, and contracts (Oesterreich \& Teuteberg, 2016), unreliable broadband connection, or lack of high-bandwidth connectivity for collaborative applications (Velocloud, 2015). Nguyen $(2018 ; 2019)$ stated that intention behavior (intended use) has a positive significant impact on the actual behavior variable. Therefore, the authors propose a hypothesis:

H11. Conditions of the business environment have a positive influence on the adoption intention.

\subsection{Adoption Intention (IA)}

According to The Theory of Planned Behavior of Ajzen (1991), behavior can be predicted or explained by the intention to carry out that behavior. The intention to approve the use of technology is an incentive to take action, make decisions about the adoption and use of technology in the future. Intention to use in the information system context is the intention of end-user to make use of the new technology (Amoako \& Salam, 2004). A study on the application of TAM to the use of information technology by Muchran and Ahmar (2019) has also applied these theories into the intention to use. Research-based on the theory of TRA and TAM by Szajna (1996) also shows a high correlation between intention to use an actual decision. Based on this, the authors propose a hypothesis:

H12. The adoption intention has a positive influence on the actual adoption of Industry 4.0.

\subsection{Actual Adoption of Industry 4.0 (AD)}

This study considers its subject here as a business. And the characteristics of the business are that this object includes many individuals inside, related to many other objects, and consciously devised beforehand to carry out the behavior. Having reasonable thinking and making rational decisions are based on available information sources. Therefore, the determinant of the use of enterprises to overcome the limitations of the TPB model that Ajzen (1991) has suggested is the factors affecting behavior such as unconscious or unfounded behavior. 


\subsection{Conceptual model}

This study is based on three main theories, which have been widely recognized and applied in many different scientific fields, namely, the Theory of Planned Behavior - TPB of Ajzen (1991) - developed from the Theory of Reasoned Action (TRA) by Ajzen and Fishbein (1975) - the Technology Acceptance Model - TAM by Davis (1989) -and C-TAM-TPB model of Taylor and Todd (1995), combining two models TPB and TAM. The research model was based on the Theory of Planned Behavior-TPB by Ajzen (1991), Technology Acceptance Model by Davis (1989), and refer to Taylor and Todd's C-TAM-TPB model (1995) to ensure the objectivity of the research model. The model uses 12 variables to interpret industrial application 4.0 of enterprises in Ho Chi Minh City.

\section{Research Method}

The hypotheses needed to build the conceptual model are examined using mixed research methods. Qualitative research and quantitative research are the two methods applied. Qualitative research is carried out with 12 participants in the business field, the questionnaire consists of two sections, which are unstructured questions and structured questions. Unstructured questions are used to refine the observed variables in the questionnaire. Structured questions have been used to examine the validity of the content. A total of 12 feedback results in the in-depth interview were used to analyze the measurement items by classifying them into three categories: "essential", "useful but non-essential" and "not necessary". The number of "essential" feedback results is used to calculate the Content Validity Ratio (CVR). According to the research results of Lawshe (1975), the formula to calculate CVR is CVR $=\{[\mathrm{Ne}-(\mathrm{N} / 2)] /(\mathrm{N} / 2)\}$. $\mathrm{Ne}$ is the number of participants who said "essential" and $\mathrm{N}$ is the total number of participants.

When the number of participants said that "essential" was greater than half of the total number of participants, the current CRV was positive, synonymous with approved variables. Conversely, if the number of participants who say "not necessary" is more than half, the CVR is now negative, meaning the variable is removed. When the number of participants said that "essential" is equal to the number of people who do not think so, this time the CVR is zero, a $5 \%$ significant level as proposed by Lawshe (1975) was adopted. Quantitative methods are applied by using questionnaires. The measurement items are measured by Likert scale ( $1=$ strongly disagree; $5=$ strongly agree). The research on applying convenient and non-probability sampling methods include 396 SMEs in Ho Chi Minh City, Vietnam then the data is analyzed based on SPSS 20 and SmartPLS 3 software.

\section{Result and Discussion}

\subsection{Qualitative Research}

This research applied an in-depth interview with 15 experts to adjust and supplement the variable and measurement items of the conceptual model. The participants were carefully selected to ensure representativeness for SMEs. Subjects interviewed with different characteristics will provide diverse and complete information of the research content to achieve the set objectives. Participants were asked some selected questions, followed by suggestions on measurement items. The original conceptual model with 12 variables and 60 measurement items developed from the theoretical basis were tested by an intensive interview method with participants. The results of the in-depth interview showed the need to eliminate five measurement items: PO5, PH5, PQ5, PE5, BR5.

\subsection{Quantitative Research}

\subsubsection{Descriptive Analysis}

This study conducted a survey of 415 SMEs, and collected 396 valid questionnaires, accounting for $95.42 \%$ (19 questionnaires were invalid). The result showed it included 230 limited companies (58.08); 94 joint-stock companies $(23.74 \%)$; 45 private enterprises $(11.36 \%)$, and 27 other firms (6.82\%). 84.34\% of SMEs adopted the three technological components of Industry 4.0 (the Cloud, Big data and analytics, and cybersecurity). $70.71 \%$ of SMEs adopted the Cloud, $74.50 \%$ SMEs adopted cybersecurity, and $64.90 \%$ SMEs adopted Big data and analytics.

\subsubsection{Exploratory Fator Analysis}

The measurement items were refined using exploratory factor analysis (EFA) and poorly fitted items were excluded. This study applied the extraction method: Principal factoring with varimax kaiser normalization rotation method. In these steps, we exclude PR4, SC1, PE4, CE2, CE4 because the factor loading of these was less than 0.5. The other measurement items were acceptable because it was larger than 0.5 (Hair et al., 1995). The value of Kaiser-MeyerOlkin of sampling adequacy $=0.879$, Bartlett's Test of Sphericity: Chi-Square $=1218.983 ; \mathrm{df}=1176 ;$ Sig. $=0,000$. Extraction Sums of Squared Loadings Cumulative $=72.174$ $\%$. Factor loadings of the indicators for each construct were statistically significant and sufficiently high to demonstrate that the indicators and their underlying constructs were accepted. The conceptual model with 12 constructs with 50 measurement items was qualified for Structural Equation Modeling analysis. 


\subsubsection{Structural Equation Modeling (SEM)}

\section{Assessment of the Model}

Partial least square structural equation modeling (PLSSEM) is a suitable technique to test the complex models which include the mediated-moderation relationships. SmartPLS 3 is the emerging SEM tool that assists the estimation process based on PLS-SEM. The result showed that the model has retained 12 constructs with 50 measurement items satisfactory continuous to further assessment. Model fit: this model presents excellent approximate goodness of fit since the value of the SRMR (Standardised Root Mean Square residual) estimated model has a value of 0.060 (saturated model), and 0.073 (estimated model) complying with the below standards described 0.08 level (Sarstedt, Ringle, \& Hair, 2017). Thus, the overall model had a good fit. This model of measurement items was consistent, there was no correlation between the measurement error should it achieved unidimensional. In the next step, we check the formative measurement models for the collinearity of indicators by looking at the formative indicators' VIF values. According to the results, VIF of the CE5 has the lowest (1.455) to the highest value of IA4 (4.092). Hence, VIF values are uniformly below the threshold value of 5 . Therefore, collinearity among the predictor constructs is not a critical issue in the structural model, and we can continue examining the results report.

\section{Valuation of the Measurement Model}

The reliability and validity analysis will be carried out through the analysis of individual reliability (factorial loads and commonality) and internal consistency (composite reliability, convergent validity through of the AVE, and finally, discriminant validity via Heterotrait-Monotrait ratio).

Internal Consistency Reliability: According to Sarstedt, Ringle, and Hair (2017), a factor displayed its reliability if its Composite. Reliability and Cronbach's alpha and Rho-A is greater than 0.7. The result showed that the Cronbach's alpha coefficient retested was from 0.783 to 0.904 , rho-A was from 0.783 to 0.915 , and Composite Reliability of all constructs in this study was from 0.873 to 0.928 (see Table 1). The results confirm the existence of good internal reliability of the measurement model.

Convergent Validity: This study checked Construct Validity both by Loadings, indicator Reliability, and Average Variance Extracted (AVE). The results showed that outer Loading of 50 measurement items was from, and Indicator reliability of 33 measurement items was from 0.736 to 0.904 larger than 0.70 and AVE of 12 constructs from 0.653 (PU) to $0.718(\mathrm{PH})$ larger than 0.5 , therefore, 9 constructs were considered to have achieved validity (Table 1).
Discriminant Validity: This study checked to construct discriminant validity by Heterotrait Monotrait (HTMT). The result showed that all constructs have excellent values well, the highest value was 0.643 , below 0.85 already supports discriminant validity (see Table 2 ).

The value $R^{2}$ : Figure 1 highlights that $r$-square $\left(R^{2}\right)$ values of all three endogenous constructs are respectively PU (0.512), followed by IA (0.439), and AD (0.333). Thus, all constructs tend to bring a $51.2 \%$ change in actual adoption Industry 4.0. These results provide clear correlation coefficients squares support for the model.

Table 1: Validity and Reliability of the Measurement Model

\begin{tabular}{|c|c|c|c|c|}
\hline Constructs & $\begin{array}{c}\text { Cronbach's } \\
\text { alpha }\end{array}$ & rho-A & CR & AVE \\
\hline AD & 0.872 & 0.884 & 0.907 & 0.661 \\
\hline BR & 0.838 & 0.840 & 0.892 & 0.673 \\
\hline CE & 0.794 & 0.803 & 0.879 & 0.709 \\
\hline IA & 0.889 & 0.891 & 0.918 & 0.692 \\
\hline PH & 0.869 & 0.872 & 0.911 & 0.718 \\
\hline PE & 0.783 & 0.783 & 0.873 & 0.697 \\
\hline PR & 0.852 & 0.862 & 0.900 & 0.694 \\
\hline PQ & 0.868 & 0.874 & 0.909 & 0.715 \\
\hline PO & 0.848 & 0.853 & 0.898 & 0.688 \\
\hline SC & 0.845 & 0.853 & 0.896 & 0.683 \\
\hline ST & 0.904 & 0.915 & 0.928 & 0.722 \\
\hline PU & 0.867 & 0.879 & 0.904 & 0.653 \\
\hline
\end{tabular}

Table 2: Construct and Hypothesis Test

\begin{tabular}{|c|c|c|c|c|}
\hline Constructs & Coefficients & $\begin{array}{c}\text { P } \\
\text { Values }\end{array}$ & \multicolumn{2}{|c|}{ Hypothesis test } \\
\hline $\mathrm{BR} \rightarrow \mathrm{IA}$ & 0.402 & 0.000 & $\mathrm{H} 10$ & Supported \\
\hline $\mathrm{CE} \rightarrow \mathrm{IA}$ & 0.263 & 0.000 & $\mathrm{H} 11$ & Supported \\
\hline $\mathrm{IA} \rightarrow \mathrm{AD}$ & 0.552 & 0.000 & $\mathrm{H} 12$ & Supported \\
\hline $\mathrm{PH} \rightarrow \mathrm{PU}$ & 0.154 & 0.001 & $\mathrm{H} 7$ & Supported \\
\hline $\mathrm{PE} \rightarrow \mathrm{IA}$ & 0.154 & 0.001 & $\mathrm{H} 9$ & Supported \\
\hline $\mathrm{PR} \rightarrow \mathrm{AD}$ & 0.126 & 0.009 & $\mathrm{H} 6$ & Supported \\
\hline $\mathrm{PR} \rightarrow \mathrm{PU}$ & 0.072 & 0.092 & $\mathrm{H} 5$ & Rejected \\
\hline $\mathrm{PQ} \rightarrow \mathrm{PU}$ & 0.155 & 0.000 & $\mathrm{H} 4$ & Supported \\
\hline $\mathrm{PO} \rightarrow \mathrm{PU}$ & 0.131 & 0.004 & $\mathrm{H} 3$ & Supported \\
\hline $\mathrm{SC} \rightarrow \mathrm{PU}$ & 0.329 & 0.000 & $\mathrm{H} 2$ & Supported \\
\hline $\mathrm{ST} \rightarrow \mathrm{PU}$ & 0.262 & 0.000 & $\mathrm{H} 1$ & Supported \\
\hline $\mathrm{PU} \rightarrow \mathrm{IA}$ & 0.104 & 0.019 & $\mathrm{H} 8$ & Supported \\
\hline
\end{tabular}




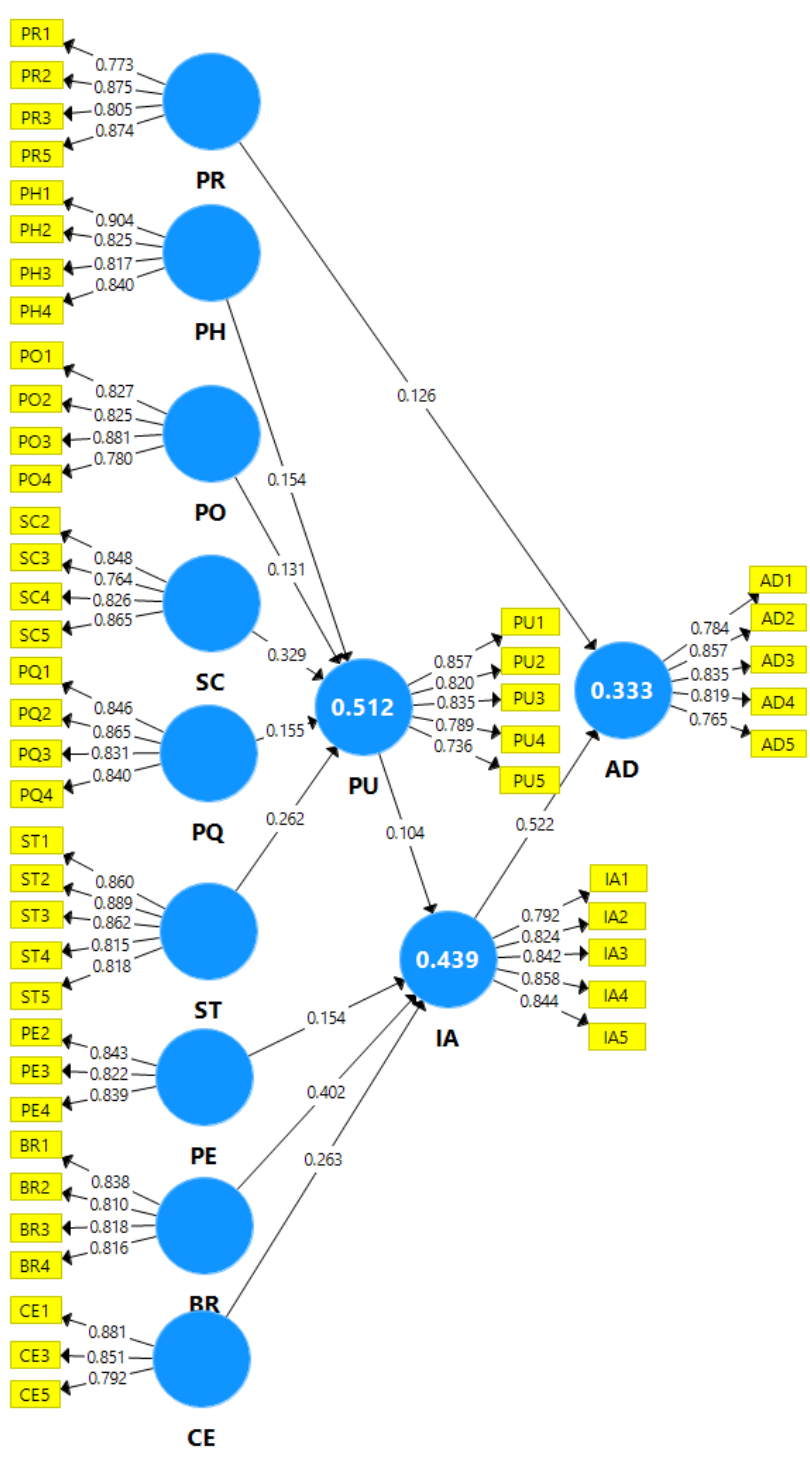

Figure 1: Structural Equation Model

The value $\mathrm{Q}^{2}$ : As can be seen, the $\mathrm{Q}^{2}$ values of three endogenous constructs are considerably above zero. More precisely, $\mathrm{Q}^{2}$ construct cross-validated redundancy of PU has the highest values $(0.324)$, followed by IA $(0.299)$, and AD $(0.212)$. These results provide clear support for the model's predictive relevance regarding the endogenous latent constructs.

\subsubsection{Hypotheses Testing}

The conceptual model and 12 hypotheses were tested using bootstrapping. Considering the results obtained
(Table 2), it indicated the value of the fit model and that the overall variables were supported. Eleven hypotheses were significant and less than the $\mathrm{p}<0.05$ level, except for H5. Overall, all the path coefficient-related hypotheses were supported from 0.104 to 0.552 (see Figure 1). Therefore, 11 hypotheses were supported and one hypothesis (H5) was rejected (see Table 2).

\subsubsection{Discussion}

The results of the study revealed that the perceived development of the human resources, perceived on-time, perceived saving cost, perceived improve product quality, and perceived saving time have a significant contribution to perceived usefulness. Perceived ease-of-use, business resources, and conditions of the business environment have an important effect on adoption intention. Perceived enhance customer relationship and adoption intention have an important effect on actual adoption of Industry 4.0 by SMEs in Ho Chi Minh City, Vietnam. These results are consistent with the literature. Generally, factors have a significant relationship with perceived usefulness, and these increase the performance, such as perceived development of human resource (Watkins \& Marsick, 1997); Perceived improve product quality (Szozda, 2017; Friederichsen \& Keller, 2014; Yin \& Qin, 2019); Perceived saving cost (Lu, 2017; Sardroud, 2012); Perceived on-time (Yuchun \& Mu, 2017; Oesterreich \& Teuteberg, 2016); and Perceived saving time (Potter, Towill \& Christopher, 2015; Santos et al., 2017).

Factors have a positive significant relationship with adoption intention (IA) such as perceived ease-of-use (Agostini \& Nosella, 2019; Erol et al., 2016; Wang Törngren, and Onori 2015; Wang, Wan \& Zhang, 2016); Business resources (Potluri \& Vajjhala, 2018; Ha, 2020); and conditions of the business environment (Yoo \& Kim, 2018). Furthermore, consistent with the results of the current study (Amoako \& Salam, 2004; Muchran \& Ahmar, 2019) the impact of adoption intention and perceived enhance customer relationship have been clarified. This study also found that adoption intention and perceived enhance customer relationship has a positive effect on actual adoption of Industry 4.0.

\section{Conclusions}

This research contributes to the analysis and understanding of the factors affecting the application of Industry 4.0 in Ho Chi Minh City, Vietnam. Based on the SEM model and the final conceptual model, there are five independent constructs such as perceived development of the human resource, perceived on-time, perceived saving cost, perceived improvement product quality, and perceived saving time that have a positive significant effect on 
perceived usefulness. Three independent constructs such as perceived ease-of-use, business resources, and conditions of the business environment have a positive impact on adoption intention. Adoption intention and perceived enhanced customer relationship has a positive effect on the actual adoption of Industry 4.0 by SMEs in Ho Chi Minh City, Vietnam.

In terms of limitations, this study considers conducting surveys of high-level personnel in enterprises to represent businesses such as $\mathrm{CEO}, \mathrm{CMO}$, and senior management. Therefore, the research results are affected in part by the subjective perception of this senior personnel, and are not yet able to fully reflect the reality of the business.

\section{Reference}

Agarwal, R., \& Prasad, J. (1997). The role of innovation characteristics and perceived voluntariness in the acceptance of information technologies. Decision Sciences, 28(3), 557-582.

Agostini, L., \& Nosella, A. (2019). The adoption of Industry 4.0 technologies in SMEs: results of an international study. Management Decision, 58(4), 625-643.

Ajzen, I. (1991). The theory of planned behavior. Organizational behavior and human decision processes, 50(2), 179-211.

Akanmu, A. \& Anumba, C. J. (2015). Cyber-physical systems integration of building information models and physical construction. Engineering, Construction, and Architectural Management 22(5), 516-535.

Amoako-Gyampah, K. (2007). Perceived usefulness, user involvement and behavioral intention: an empirical study of ERP implementation. Computers in human behavior, 23(3), 1232-1248.

Amoako-Gyampah, K., \& Salam, A. F. (2004). An extension of the technology acceptance model in an ERP implementation environment. Information\&management, 41(6), 731-745.

Davis, F. D. (1989). Perceived Usefulness, Perceived Ease of Use, and User Acceptance of Information Technology. MIS Quarterly, 13(3), 319-339.

Erol, S., Jäger, A., Hold, P., Ott, K., \& Sihn, W. (2016). Tangible Industry 4.0: a scenario-based approach to learning for the future of production. Procedia CiRp, 54(1), 13-18.

Fishbein, M., \& Ajzen, I. (1975). Intention and Behavior: An introduction to theory and research.

Friederichsen, M. R. M. B. N., \& Keller, M. (2014). How virtualization, decentralization and network building change the manufacturing landscape: An Industry 4.0 perspective. International Journal of Mechanical, Aerospace, Industrial, Mechatronic and Manufacturing Engineering, 8(1), $37-44$.

Fonseca, L. M. (2018, May). Industry 4.0 and the digital society: concepts, dimensions and envisioned benefits. In Proceedings of the international conference on business excellence (Vol. 12, No. 1, pp. 386-397). Sciendo.

Gourlay, C. (1999). Partners apart: managing civil-military cooperation in humanitarian interventions. UNIDIR.

Green, G. C., Hevner, A. R., \& Collins, R. W. (2005). The impacts of quality and productivity perceptions on the use of software process improvement innovations. Information and Software Technology, 47(8), 543-553.

Ha, V. D. (2020). Impact of Organizational Culture on the Accounting Information System and Operational Performance of Small and Medium Sized Enterprises in Ho Chi Minh City. Journal of Asian Finance, Economics and Business, 7(2), 301-308. https://doi.org/10.13106/jafeb.2020.vol7.no2.301.

Hair, J. F., Black, W. C., Babin, B. J., Anderson, R. E., \& Tatham, R.L. (1995). Multivariate data analysis (4th ed.). USA: Prentice-Hall, Inc.

Harrigan, P., Ramsey, E., \& Ibbotson, P. (2011). Critical factors underpinning the e-CRM activities of SMEs. Journal of Marketing Management, 27(5-6), 503-529.

Kopetz, H. (2011). Real-time systems: design principles for distributed embedded applications. Springer Science \& Business Media.

Lawshe, C. H. (1975). A quantitative approach to content validity 1. Personnel Psychology, 28(4), 563-575.

Leong, L. Y., Ooi, K. B., Chong, A. Y. L., \& Lin, B. (2011). Influence of individual characteristics, perceived usefulness and ease of use on mobile entertainment adoption. International Journal of Mobile Communications, 9(4), 359-382.

Lin, H. F. (2011). An empirical investigation of mobile banking adoption: The effect of innovation attributes and knowledge-based trust. International journal of information management, 31(3), 252-260.

Lonn, S., \& Teasley, S. D. (2009). Saving time or innovating practice: Investigating perceptions and uses of Learning Management Systems. Computers \& Education, 53(3), 686694.

Lu, Y. (2017). Industry 4.0: A survey on technologies, applications and open research issues. Journal of Industrial Information Integration, 6, 1-10.

Matopoulos, A., \& Bourlakis, M. (2011). Identifying innovation strategies: insights from the Greek food manufacturing sector. International Journal of Innovation and Regional Development, 3(2), 159-173.

Mavri, M. (2015). Redesigning a Production Chain Based on 3D Printing Technology. Knowledge and Process Management, 22(3), 141-147.

Moeuf, A., Pellerin, R., Lamouri, S., Tamayo-Giraldo, S., \& Barbaray, R. (2018). The industrial management of SMEs in the era of Industry 4.0. International Journal of Production Research, 56(3), 1118-1136. 
Muchran, M., \& Ahmar, A. S. (2019). Application of TAM model to the use of information technology. arXiv preprint arXiv:1901.11358.

Nguyen, T. H., Newby, M., \& Macaulay, M. J. (2015). Information technology adoption in small business: Confirmation of a proposed framework. Journal of Small Business Management, 53(1), 207-227.

Nguyen, X. T. (2018). The Impact of Hallyu 4.0 and Social Media on Korean Products Purchase Decision of Generation C in Vietnam. Journal of Asian Finance, Economics, and Business, 5(3) 81-93. http://doi.org/10.13106/jafeb.2018.vol5.no3.81.

Nguyen, X. T. (2019). Factors impacting on Korean consummer goods purchase decision of Vietnam's generation Z. Journal Distribution Science, 17(10), 61-71.

Oesterreich, T. D. \& Teuteberg, F. (2016). Understanding the implications of digitisation and automation in the context of Industry 4.0. Computers in Industry, 83, 121-139.

Potluri, R. M., \& Vajjhala, N. R. (2018). A Study on Application of Web 3.0 Technologies in Small and Medium Enterprises of India. Journal of Asian Finance, Economics and Business, 5(2), 73-79. https://doi.org/10.13106/jafeb.2018.vol5.no2.73.

Potter, A., Towill, D. R, \& Christopher, M. (2015). Evolution of the migratory supply chain model. Supply Chain Management A International Journal, 20(6), 603-612.

Radziwon, A., Bilberg, A., Bogers, M., \& Madsen, E. S. (2014). The smart factory: exploring adaptive and flexible manufacturing solutions. Procedia Engineering, 69, 1184-1190.

Rüßmann, M., Lorenz, M., Gerbert, P., Waldner, M., Justus, J., Engel, P., \& Harnisch, M. (2015). Industry 4.0: The future of productivity and growth in manufacturing industries. Boston Consulting Group, 9(1), 54-89.

Santos, K., Loures, E., Pjechnicki, F., Canciglieri, O. (2017). Opportunities Assessment of Product Development Process in Industry 4.0. Procedia Manufacturing, 11(1), 358-1365.

Sardroud, J. M. (2012). Influence of RFID technology on automated management of construction materials and components. Scientia Iranica, 19(3), 381-392.

Sarstedt, M., Ringle, C. M., \& Hair, J. F. (2017). Partial least squares structural equation modeling. Handbook of market research, 26, 1-40.

Schwab, K. (2017). The Fourth Industrial Revolution. New York: Crown Publishing Group.

Smith, P. (2014). BIM \& the 5D Project Cost Manager. Procedia Social and Behavioral Sciences, 119, 475-484.

Suki, N. M., \& Suki, N. M. (2011). Exploring the relationship between perceived usefulness, perceived ease of use, perceived enjoyment, attitude and subscribers' intention towards using 3G mobile services. Journal of Information Technology Management, 22(1), 1-7.
Sundblad, W. (2018). How Industry 4.0 Helps Manufacturers Solve Workforce Challenge Retrieved 20 May 2019 From https:// www.forbes.com/sites/willemsundbladeurope/2018/08/28/ how-industry-4-0-helps-manufacturers-solve-workforcechallenges/

Szajna, B. (1996). Empirical evaluation of the revised technology acceptance model. Management Science, 42(1), 85-92.

Szozda, N. (2017). Industry 4.0 and its impact on the functioning of supply chains. LogForum, Scientific Journal of Logistics, 13(4), 401-414.

Taylor, S., \& Todd, P. A. (1995). Assessing IT usage: The role of prior experience. MIS Quarterly. 19(4), 561-570.

UNIDO. (2016). Opportunities and Challenges of the New Industrial Revolution for Developing Countries and Economies in Transition. Retrieved 20 May 2019 from www.unido. org/fileadmin/user_media_upgrade/Resources/Publications/ Unido_industry-4_NEW.pdf.

Velocloud. (2015). Devcon Provides Reliable Access to Cloud Apps and Improves Remote Collaboration. Retrieved 20 May 2020 from: http://www.velocloud.com/ customers/case-studydevcon.

Venkatesh, V., Morris, M. G., Davis, G. B., \& Davis, F. D. (2003). User acceptance of information technology: Toward a unified view. MIS Quarterly, 27(3), 425-478.

Wang, L., Törngren, M., \& Onori, M. (2015). Current status and advancement of cyber-physical systems in manufacturing. Journal of Manufacturing Systems, 37, 517527.

Wang, S., Wan, J., Li, D., \& Zhang, C. (2016). Implementing smart factory of industrie 4.0: an outlook. International Journal of Distributed Sensor Networks, 12(1), 3159805.

Watkins, K. E., \& Marsick, V. J. (1997). Dimensions of the learning organization questionnaire. Warwick, RI: Partners for the learning organization.

Yin, Y., \& Qin, S. F. (2019). A smart performance measurement approach for collaborative design in Industry 4.0. Advances in Mechanical Engineering, 11(1), 1-15.

Yoo, S. K., \& Kim, B. Y. (2018). The Effective Factors of Cloud Computing Adoption Success in Organization. The Journal of Asian Finance, Economics and Business, 6(1), 217-229. http:// doi.org/10.13106/jafeb.2019.vol6.no1.217.

Yuchun, X. \& Mu, C. (2017). An Internet of Things based framework to enhance just-in-time manufacturing. The Journal of Engineering Manufacture, 232(13), 2353-2363.

Zhou, K., Liu, T., \& Zhou, L. (2015, August). Industry 4.0: Towards future industrial opportunities and challenges. In 2015 12th International Conference on fuzzy systems and knowledge discovery (FSKD) (pp. 2147-2152). IEEE. 